\title{
Analysis of Lift-Generating Disk Type Blade Wind Power System Using Modelica
}

\author{
Yeongmin Yoo ${ }^{1}$ Soyoung Lee ${ }^{1} \quad$ Jaehyun Yoon $^{1} \quad$ Jongsoo Lee $^{1}$ \\ ${ }^{1}$ Department of Mechanical Engineering, Yonsei University, Seoul, Korea, \\ \{yym9514, leesoy77, yunjh00, jleej\}@yonsei.ac.kr
}

\begin{abstract}
The research and application technology of wind power generation have attracted great attention in relation to the development of renewable energy. As wind power systems such as a propeller type are being enlarged to increase power output, various problems such as natural landscaping damage and shadow problems are occurring. In this paper, we propose a lift-generating disk type blade power generation mechanism that can effectively generate wind power even with simple structure considering the problems of existing system. The modeling method of the wind power system is explained using the Modelica. After that, a wind tunnel test is conducted through a small scale model of the disk type blade created for simulation verification. As a result, the modeling of the wind power system is verified and the results of the generator power output are presented through simulation.
\end{abstract}

Keywords: Wind Power System, Disk Type Blade, Multi-Physics System, Integrated Simulation

\section{Introduction}

Wind power technology is one of the various methods of obtaining electricity from natural energy and has received much attention because it can use infinite resources for free. Thus, wind energy is expected to play a decisive role in the future world energy supply. To produce wind power system (WPS), efficiency of development is required to lower development cost. With this objective, computer simulation technology is used in all development fields. Therefore, the simulation technique is a very important means for streamlining development work. The WPS to be designed includes various physical phenomena such as mechanical dynamics, electricity, control and flow, and a program suitable for the required integrated simulation of the system. Typically, different development departments often use different software because they deal with different physical phenomena. Thus, a dedicated analysis software must be employed for detailed analysis. However, it is difficult for this design method to effectively cope with frequent design changes occurring in the initial conceptual design, which results in unnecessary work and, reduction in efficiency. In the initial design phase, it is necessary to use integrated simulation software because it is important to communicate, coordinate, and cross check between concept verification and development personnel rather than conduct detailed analysis.

For this reason, the Modelica language is adopted for integrated simulation. So far, various researches on WPS using Modelica have continued. Strobel et al. (Strobel, 2011) proposed a Modelica library by designing offshore WPS and verifying simulation results. Petersson et al. (Petersson, 2012) presented a mathematical modeling of a vertical axis WPS and presented simulation results accordingly. Eberhart et al. (Eberhart, 2015) constructed an open source library for the simulation of the horizontal axis WPS.

In this study, a new type of WPS utilizing Modelica is designed based on these studies. The conventional WPS is called a horizontal-axis-type WPS because the rotation axis of the blade is placed horizontally. These types of blades have characteristics suitable for highspeed rotation, but various problems, such as modification of landscapes for natural environment, and social pressure issues because of the shadows cast by the structures are raised. Therefore, it is the aim of the authors to design a lift-generating disk type WPS that can generate electricity in response to an omni directional wind instead of a conventional WPS. The disk type blades were first designed using computeraided design (CAD), and then they were designed according to design parameters. We designed the WPS by applying the designed blade to Modelica simulation. Wind tunnel test were performed for simulation verification and the results were in good agreement. Finally, we designed the Modelica simulation to derive the generator power output of the disk type blade WPS.

\section{System Mechanism}

The proposed WPS is shown in Figure 1. The system in which the blade is disk type and power is generated while it moves along a vertical direction. The basic principle of the system is that vertically supported tower structures from the ground move along the vertical axis with the disk type blade lifted by the wind. This type of system generates electric energy through a 


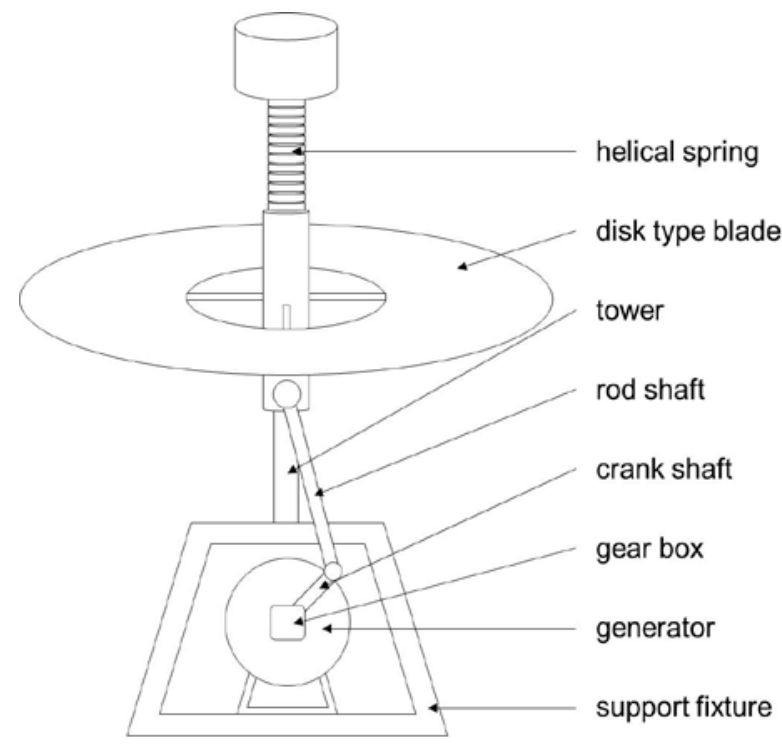

Figure 1. Schematic diagram of the lift-generating disk type wind power generation system.

power transmission system (PTS) that converts such motion into rotary motion along with a power conversion system (PCS), such as a generator. This model is very different from typical WPS, such as conventional horizontal or vertical axis turbines. The proposed WPS is advantageous for areas in which flow-induced noise and blade flickering/shadows become critical. The small scale WPS developed by the authors includes a disk type blade, spring for managing vibration generated by the vertical movement of the blade, crank-rod mechanism (Khemili, 2008) for converting vertical motion into rotational motion, and tower for installing a system. Thus, through this PTS, power is produced by the generator.

The proposed disk type blade has some distinct characteristics. First, the disk can move up and down to generate lift force that is converted into electrical energy. Second, owing to its symmetric shape, it is easily activated by the wind coming from all directions. Finally, the proposed model has a relatively weak contibution to shadow flickering because it does not feature multi-blade rotation and the space required for realizing its motion is comparatively small.

\section{System Modeling}

\subsection{Shape Design of Disk Type Blade}

The shape of the disk type blade to be designed using CAD is shown in Figure 2. The material used for the blades is polymer-type polycarbonate with a density of $1.12 \mathrm{e}^{3} \mathrm{~kg} / \mathrm{m}^{3}$, Young's modulus was $2.3 \mathrm{e}^{9} \mathrm{~Pa}$, and Poisson's ratio of 0.33 . The disk type blade is hollow, and its shell thickness is $10.3 \mathrm{~mm}$. The shape was designed considering the force acting on the blade. The lift and drag are different depending on the shape. For instance, the longer the airfoil chord length of the blade

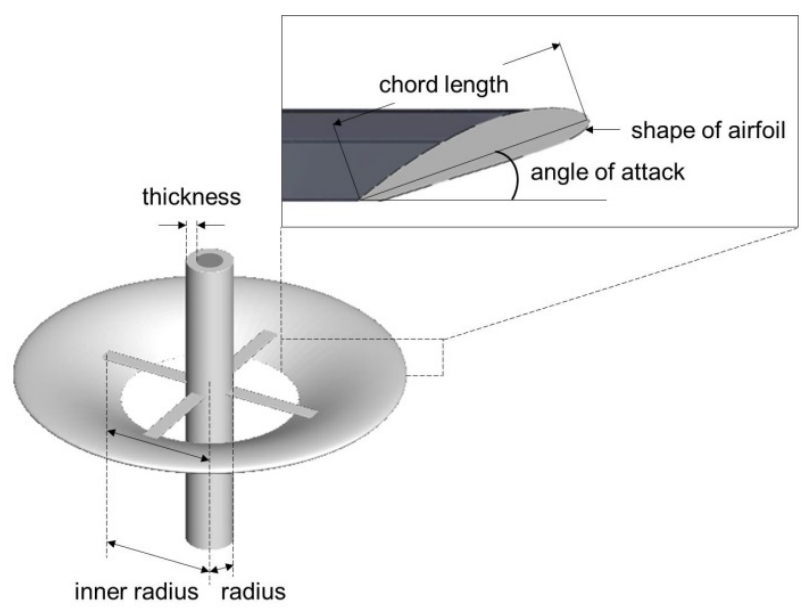

Figure 2. Geometric model and design parameters of a disk type blade.

is, the more lift can be generated. However, such a longer length increases the weight of the product, resulting in a non-economical design. Considering these conditions, analysis of parameters that affect the shape design was carried out in order to create a lightweight blade with minimal airfoil chord length. Additionally, the fixed variables and control variables to be changed were accordingly selected. As fixed variables, the radius of the center tower connected to the blade is $0.30 \mathrm{~m}$, thickness is $0.05 \mathrm{~m}$, and the inner radius between the tower and the disk type blade is $0.55 \mathrm{~m}$. For the aforementioned fixed parameters, a total of 3 disk type blade parameters, such as the airfoil chord length, angle of attack (AOA), and NACA series airfoil cross-section shape of the blade are designated as design variables, as shown Table 1.

For each parameter, the three values represent the three levels considered when varying the design of the experiment. The chord lengths were $0.20 \mathrm{~m}, 0.45 \mathrm{~m}$, and $0.70 \mathrm{~m}$. The values of the AOA were $5^{\circ}, 10^{\circ}$, and $15^{\circ}$. For the NACA series, the airfoil section was selected from NACA632615, NACA64A410, and NACA631412, and the airfoils were cambered. In this study, we used a central composite design (CCD) table that allowed the smallest number of numerical experiments.

Table 1. Design variables of a disk type blade.

\begin{tabular}{|c|c|c|c|c|}
\hline$x_{1}$ & $\begin{array}{c}\text { Factor } \\
\text { chord length } \\
(\mathrm{m})\end{array}$ & 0.20 & 0.45 & 0.70 \\
\hline$x_{2}$ & $\begin{array}{c}\text { angle of attack } \\
\left({ }^{\circ}\right)\end{array}$ & 5 & 10 & 15 \\
\hline$x_{3}$ & shape of airfoil & 632615 & $64 \mathrm{~A} 410$ & 631412 \\
\hline
\end{tabular}


In the CCD, the overall number of experiments was 15 , wherein the value of $\alpha$ for each design variable was \pm 4.20 in $x_{1}$, and \pm 8.41 in $x_{2}$. Particularly in $x_{3}$ of the NACA series, $-\alpha$ was selected using the level-1 value of NACA632615, and $+\alpha$ was selected using the level3 value of NACA631412. The CCD method was applied to derive the blade shape of 15 cases according to design variables (Montgomery, 2017).

\subsection{Computational Fluid Dynamics Simulation}

Flow simulation was conducted using ANSYS ICEMCFD for computational fluid dynamics (CFD) simulations. The governing equations solved in the fluid domain were the incompressible Navier-Stokes equations with the Reynolds stress term. The Reynolds stress was treated as a shear gradient and eddy viscosity in the Boussinesq approximation. The inlet wind speed in the present study was $12 \mathrm{~m} / \mathrm{s}$, which is the standard speed for small scale WPS. When the projection diameter of the blade was set to be the characteristic length with this inlet velocity, the Reynolds number became 861,000-2,100,000 considering the wind speed, the disk diameter, and the air viscosity.

We built the tetrahedral mesh in the fluid domain. The unit size for this mesh was $0.012 \mathrm{~m}$, and the ratio of the maximal size to the unit size was 20. A finer mesh was set near the disk type blade and tower, while a coarser mesh was set in the region that was far away from the disk type blade. There were 7 million mesh cells. The boundary conditions of the flow simulation were location-dependent. The inlet condition was Dirichlet's boundary condition, according to which boundary nodes had a constant velocity. The outlet condition was the open boundary condition, which prescribes zero static pressure for no disturbance of the fluid motion by the boundaries. The boundary condition at the surface was the no-slip condition, according to which the flow velocity is zero. Other boundary conditions were related to some initial conditions. Figure 3 shows the CFD simulation results for the blade designed by the CCD method. From this result, we want to confirm the response of the system according to lift and drag values.

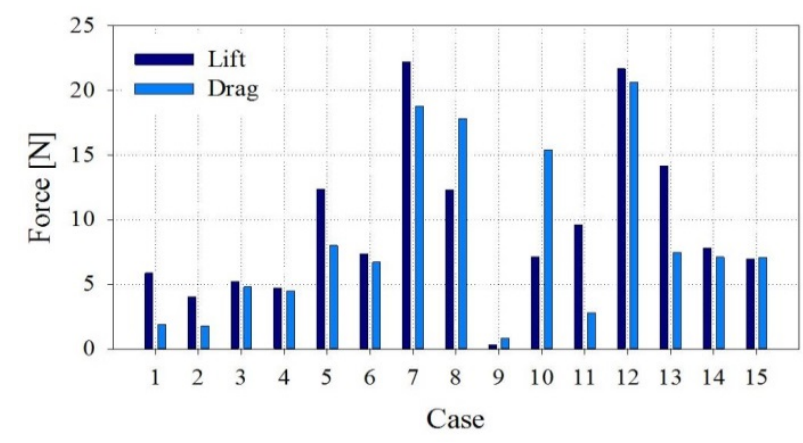

Figure 3. CFD simulation results using CCD method.
The case that generates the largest lift is Case 7, but the simulation is compared with several cases in order to confirm that the output of the WPS is the best. For example, we will compare the smallest lift case and the largest drag case.

\subsection{Integrated Simulation using Modelica}

Modelica is an object-oriented simulation language developed to simulate complex and large heterogeneous physics. It is more practical to implement simulation because it has an acausal relationship with the elements of the before and after steps even if the elements needing modifications are changed during the course of the simulation design through acausal programming (Mattsson, 1998). In order to conveniently model a system, such as a WPS, a study was conducted using a multibody system library that provides a three-dimensional mechanical component.

The two primary forces acting on the disk type blade are lift and drag. In order to simulate the lift-generating disk type WPS, the lift force in the y-axis direction and the drag in the $\mathrm{x}$-axis direction were selected as input values. Each force acting on the blade was applied with a constant value and design was carried out with the force acting on the center of mass of the blade. Since the blade model is considered as a rigid body in Modelica, the mass, center of mass, and inertia tensor are selected as input variables. These data were applied as parameter values to MultiBody.Parts.Body. The MultiBody.Parts.BodyCylinder was selected as a cylindrical tower with a diameter of $0.25 \mathrm{~m}$ and height of $10 \mathrm{~m}$. The disk type blade is a system that reciprocates vertically along the vertical axis and can not utilize the rotational force generated from the rotor shaft as the blades and rotors of existing WPS rotate. Therefore, a crank-rod mechanism is considered to convert the motion of the disk type blade into rotational motion. Table 2 shows the parameters for PTS and PCS mechanism design included in the WPS.

Table 2. Specifications for the PTS and PCS mechanism.

\begin{tabular}{|c|c|c|}
\hline Component & Parameter & Value \\
\hline \multirow{2}{*}{ crank } & $\begin{array}{c}\text { mass } \\
(\mathrm{kg})\end{array}$ & 3.08 \\
\cline { 2 - 3 } rod & $\begin{array}{c}\text { length } \\
(\mathrm{m})\end{array}$ & 1 \\
\cline { 2 - 3 } & $\begin{array}{c}\text { mass } \\
(\mathrm{kg})\end{array}$ & 9.24 \\
\hline gear box & $\begin{array}{c}\text { length } \\
(\mathrm{m})\end{array}$ & 3 \\
\hline generator & $\begin{array}{c}\text { gear ratio } \\
\text { moment of inertia } \\
\left(\mathrm{kg} \cdot \mathrm{m}^{2}\right)\end{array}$ & 0.0035 \\
\hline
\end{tabular}


These values were selected considering the small-scale WPS (Lim, 2017). The length of the crank with the rod was calculated to allow the crank to rotate in a circle according to the displacement of the blade. The models were designed using MultiBody.Parts.BodyBox and the selected parameters were applied as input values. For connecting the system, MultiBody.Joints.Revolute is the connection model used that connects the system. The rotation speed of the low speed shaft is increased by the gearbox ratio whereas torque is reduced. The torque in the high-speed shaft connected from the gear model is used for the rotation of the generator and the generation of the torque drawn out from the generator. The power of the system was finally obtained by using the angular velocity and torque output from the generator. Figure 4 is model of whole system in OpenModelica.

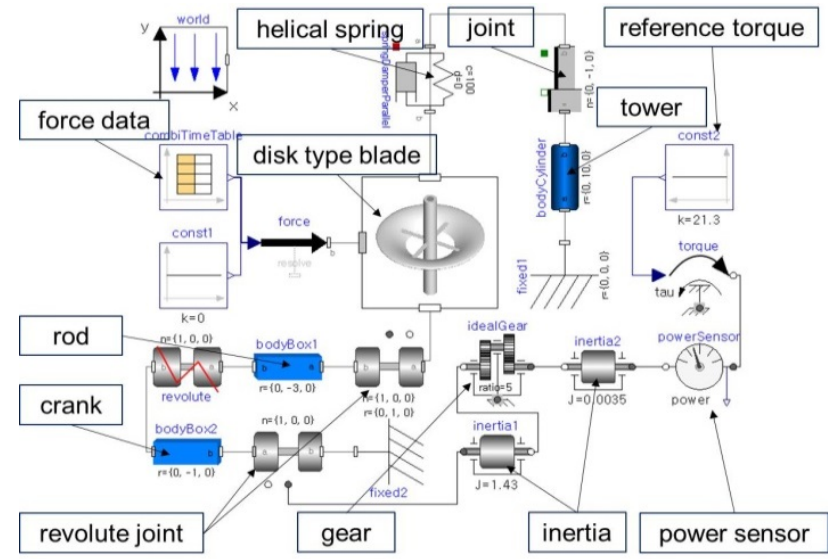

Figure 4. Model of lift-generating disk type wind power generation system in OpenModelica.

\section{Simulation Verification}

\subsection{Experiment Composition}

The wind tunnel test was conducted for the simulation verification of the WPS designed based on the Modelica and compared with the experimental data. Among the 15 blade types, the case where the most lift occurs is Case 7 , and the AOA is $15^{\circ}$. Based on this, the blade is reduced in size by $1: 10$ and $1: 15$. The 4 reduced models (Case A, B, C, and D) are manufactured by 3D printer. In the case of the blade shape derived from the CCD method, the reduced model corresponding to case 7 was Case C. Based on this, Case $\mathrm{A}$ and $\mathrm{D}$ had the same AOA. To compare various results, Case $B$ was made by greatly increasing the AOA. In addition, Case A and B were solid types, and Case $\mathrm{C}$ and $\mathrm{D}$ were hollow.

The wind tunnel test equipment was $300 \mathrm{~mm}$ in height, $400 \mathrm{~mm}$ in width, 1,200 $\mathrm{mm}$ in length and the maximum wind speed was increased to $20 \mathrm{~m} / \mathrm{s}$. Experiments were carried out to observe the upward displacements of the fabricated small scale model blades with varying wind speeds. As the vertical displacement of the disk type blade increased, the upward movement was observed in Case $\mathrm{C}$ and $\mathrm{D}$, and the Case $\mathrm{A}$ and $\mathrm{B}$ did not move, so the displacement result could not be obtained. Case $A$ is a 1:15 small scale model. Since the area under pressure is small, the generation of lift for disk movement is not sufficient. In Case $\mathrm{B}$, there was no change of motion up to wind speed of $20 \mathrm{~m} / \mathrm{s}$, because the weight increased due to the rise of the angle of attack. In Case $\mathrm{C}$, the movement was observed at wind speeds of $12 \mathrm{~m} / \mathrm{s}$ or more, and it was confirmed that the maximum movement was 110 $\mathrm{mm}$. In Case $\mathrm{D}$, the movement was observed at wind speeds of $12 \mathrm{~m} / \mathrm{s}$ or more, and it rose up to $40 \mathrm{~mm}$, but increased at a much lower rate than Case C.

\subsection{Validation}

As a result of the wind tunnel test, we compare the experimental value and the simulation value for Case C, which showed a large upward movement in the wind speed range of 12 20 m/s. As shown in Figure 5, the simulation design was constructed considering the wind tunnel test environment.
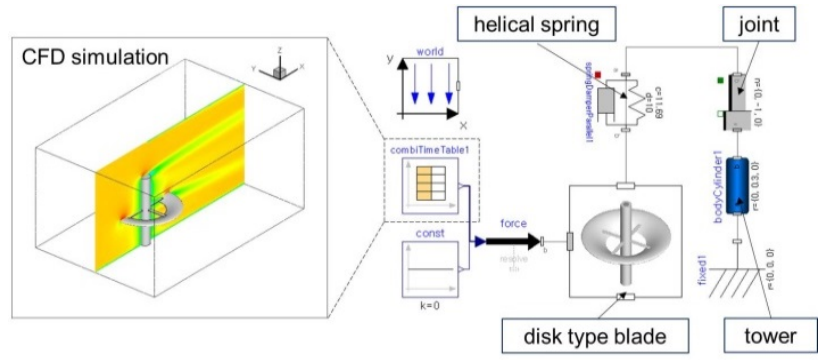

Figure 5. Modeling of 3D printing disk type blade in OpenModelica for simulation verification.

Experiments were performed to obtain the upward displacement of the blades at the wind speeds of 12, 15 and $20 \mathrm{~m} / \mathrm{s}$. The lifting force derived from the CFD simulation under the same conditions as the experimental environment was applied to the Modelica to obtain the upward displacement of the blade. The comparison between the wind tunnel test result and the Modelica simulation result is shown in Figure 6.

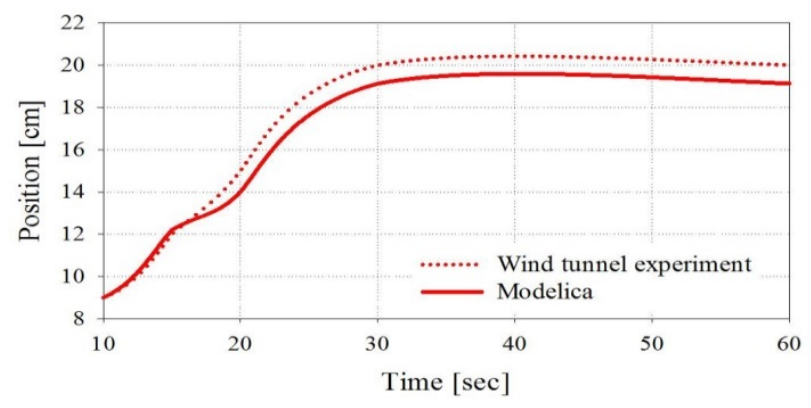

Figure 6. Simulation verification results compared with wind tunnel test. 
The initial position of the small scale model is $90 \mathrm{~mm}$. The simulated time was 60 seconds considering actual wind tunnel test time. Through these comparisons, it can be seen that the experimental results and the simulation results are similar.

\section{Results and Discussions}

Through this study, we apply the lift derived from CFD simulation to Modelica and compare the power of the WPS according to the blade shape. It is to derive the results with only the simulation. Among the 15 types of blades designed by CCD method, the comparison objects are as follows:

- Case 2 and 7 were selected to compare the case that generates the lowest lift and the highest.

- Case 7 and 12 were selected to compare the case that generates the highest lift and highest drag.

The generator power results for the WPS of the three blade cases are shown in Figure 7. In order to compare the blade with the lowest and highest lift, the average power for one hour was obtained. Case 9 was excluded from the case of the lowest lift because the drag force was large. Case 2 (chord length $0.2 \mathrm{~m}, \mathrm{AOA} 5^{\circ}$ ) is $0.437 \mathrm{~kW}$ and Case 7 (chord length $0.7 \mathrm{~m}$, AOA 15 $5^{\circ}$ ) is $0.530 \mathrm{~kW}$. It can be seen that the larger the lift generated on the blade, the higher the average power. Case 12 (chord length $0.45 \mathrm{~m}, \mathrm{AOA} 23.41^{\circ}$ ) is 0.514 $\mathrm{kW}$. This is the case where the lift is higher than Case 2 and similar to Case 7, but the drag is the largest. From the simulation results, it can be seen that the Case 7, which has the highest lift, has the highest average power of the WPS. Therefore, it is possible to derive the power of the proposed system through simulation.
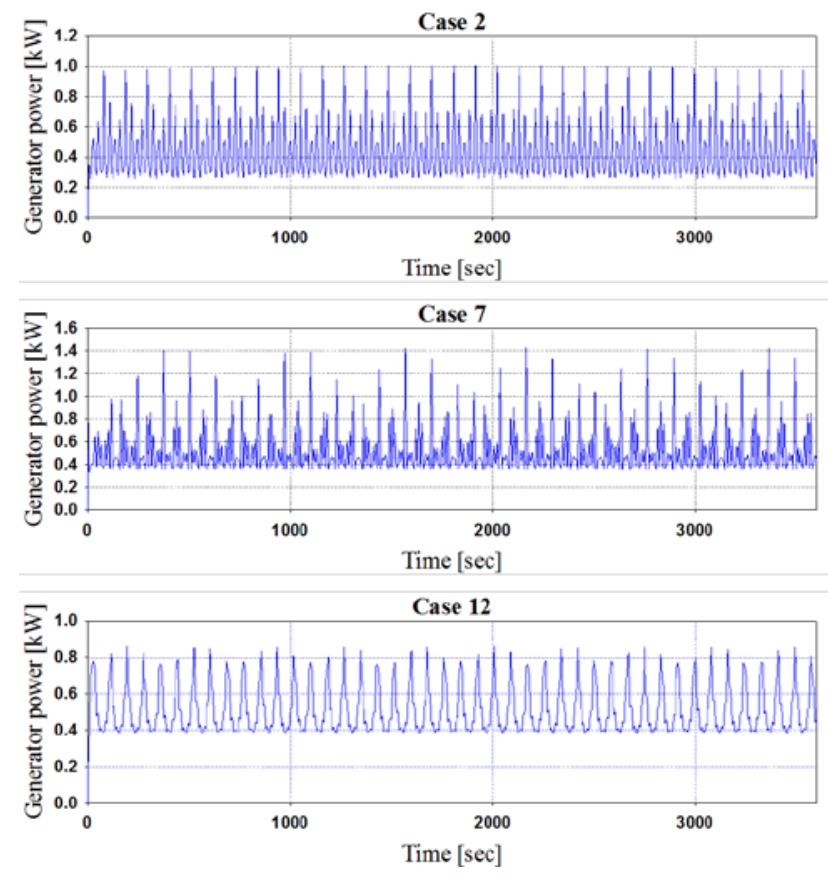

Figure 7. Simulation results of generator power output.

\section{Conclusions}

Considering the various problems of the conventional WPS, a mechanism of a generation system of a disk type blade capable of generating wind power with a simple structure is proposed. In order to determine the disk type blade shape, three design parameters affecting the generation of lift were selected and 15 blade shapes were constructed by applying the CCD method. CFD simulation was carried out to derive lift force data for the designed blades and a constant wind speed condition of $12 \mathrm{~m} / \mathrm{s}$ was applied. We modeled disk type blade, springs, tower, crank, gearbox, generator, etc. for integrated simulation and conducted simulation verification through wind tunnel test. In order to compare the power of the WPS according to the influences of the design variables among the blades, comparison was made with three blade cases. In the wind tunnel test, as shown in Figure 6, the blades were vertically moved up to the final wind speed of $20 \mathrm{~m} / \mathrm{s}$ and almost stopped. Because the blade of the reduced model used in the experiment is light in weight, it only moves upward. However, in the simulations designed considering PTS and PCS, the blades periodically move according to the increase of the blade weight and the spring constant, and it is confirmed that the power is derived as shown in Figure 7.

As a result, the mechanism of the WPS for the new type of blades was established and the power result for the system was derived by applying the simulation technique.

\section{Acknowledgements}

This research is supported by Hyundai NGV (No.201611-0906) and the Basic Science Research Program through the National Research Foundation of Korea (NRF), funded by the Ministry of Science, ICT \& Future Planning (2017R1A2B4009606).

\section{References}

Strobel M, Vorpahl F, Hillmann C, Gu X, Zuga A, and Wihlfahrt U. The Onwind Modelica Library for Offshore Wind Turbines-implementation and First Results. Proceedings of the 8th International Modelica Conference, March 20-22, 2011, Dresden, Germany.

Petersson J, Isaksson P, Tummescheit $\mathrm{H}$, and Ylikiiskila $\mathrm{J}$. Modeling and Simulation of a Vertical Wind Power Plant in Dymola/Modelica. Proceedings of the 9th International Modelica Conference, September 3-5, 2012, Munich, Germany.

Eberhart P, Chung TS, Haumer A, and Kral C. Open Source Library for the Simulation of Wind Power Plants. Proceedings of the 11th International Modelica Conference, September 21-23, 2015, Versailles, France.

Khemili I and Romdhane L. Dynamic Analysis of a Flexible Slider-Crank Mechanism with Clearance. European Journal of Mechanics A-Solids, 27(5):882-98, 2008. 
Montgomery DC, Design and Analysis of Experiments. $9^{\text {th }}$ ed. John Wiley and Sons Press, New Jersey, 2017.

Mattsson SE, Elmqvist H, and Otter M. Physical System Modeling with Modelica. Control Engineering Practice, 6(4):501-10, 1998.

Lim CW, Design and Manufacture of Small-Scale Wind Turbine to emulate Torque Response of MW Wind Turbine. International Journal of Precision Engineering and Manufacturing-Green Technology, 4(4):409-418, 2017. 